\title{
Keragaman Fenotipe Bentuk-Bentuk Tubuh Sapi Hasil Persilangan Pejantan Brahman dengan Indukan Bali
}

\author{
Susril Dendi Efendi ${ }^{1 *}$, Junaedi ${ }^{1}$, Suparman $^{1}$, Khaeruddin $^{2}$ \\ ${ }^{1}$ Program Studi Peternakan, Fakultas Pertanian Perikanan dan Peternakan, Universitas Sembilanbelas November Kolaka. \\ Jl. Pemuda No. 339, Kolaka 93517, Sulawesi Tenggara, Indonesia \\ ${ }^{2}$ Program Studi Peternakan, Fakultas Pertanian, Universitas Muhammadiyah Sinjai. \\ Jl. Teuku Umar No. 8, Biringere, Sinjai Utara 92611, Sulawesi Selatan, Indonesia \\ *uccillahay@gmail.com
}

\section{INFORMASI \\ ARTIKEL}

Diterima 01 Desember 2021

Hasil revisi diterima 02

Desember 2021

Diterbitkan 02

Desember 2021

Publish online 02

Desember 2021

Kata-kata kunci:

Sapi Brahman;

Sapi Bali;

Fenotipe;

Persilangan;

Bentuk tubuh;

\section{ARTICLE INFO}

Article history

Received 01 December 2021

Received in revised from 02 December

2021

Accepted 02 December 2021

Available online. 02 December 2021

\section{ABSTRAK}

Penelitian ini bertujuan untuk mengidentifikasi keragaman fenotipe bentuk-bentuk tubuh sapi hasil persilangan pejantan brahman dengan indukan sapi bali. Penelitian ini dilakukan di wilayah Kecamatan Watubangga, Toari dan Tanggetada, kabupaten Kolaka menggunakan sapi hasil persilangan pejantan Brahman dengan indukan Bali sebanyak 100 sampel. Penelitian dilakukan dengan metode survey. Parameter yang diamati berupa sifat kualitatif meliputi; garis punggung gelambir, punuk, bentuk tanduk, dan bentuk telinga. Data sifat kualitatif ditabulasi dan dihitung frekuensi fenotipnya. Sapi hasil persilangan pejantan Brahman dengan indukan Bali memiliki garis punggung sebanyak $13 \%$ dan didominasi oleh sapi keturunan tidak memiliki garis punggung (87\%). Sapi hasil persilangan pejantan Brahman dengan indukan Bali memiliki gelambir sebanyak 67\% dan tidak bergelambir sebanyak $33 \%$. Sapi hasil persilangan pejantan Brahman dengan indukan Bali didominasi oleh fenotipe yang tidak berpunuk (78\%) dibanding sapi hasil silangan berpunuk (22\%). Bentuk tanduk sapi hasil pesilangan pejantan Brahman dengan indukan Bali terdapat lima variasi, frekuensi fenotip sapi bertanduk sebanyak 91\%, tidak bertanduk 9\%. Sapi hasil persilangan pejantan Brahman dengan indukan Bali memiliki bentuk telinga tegak sebanyak $32 \%$ dan telinga tidak tegak $68 \%$. 
Key Words:

Brahman bull;

Bali cattle;

Phenotype;

Crossess;

Body parts shape; and is dominated by cows that do not have a dorsal line (87\%). The crossbreeding of Brahman bulls with Balinese breeds had $67 \%$ of wavy and $33 \%$ of non-slapped cows. The crossbreeding of Brahman bulls with Balinese breeds was dominated by the humpless phenotype (78\%) compared to the hump-crossed cattle (22\%). There are five variations of the horn shape of the cross between Brahman males and Balinese breeds, the phenotype frequency of horned cows is $91 \%$, without horns is $9 \%$. The crossbreeding of Brahman bulls with Balinese breeds had erect ears as much as $32 \%$ and ears not erect as much as $68 \%$.

\section{PENDAHULUAN}

Indonesia dikenal sebagai salah satu negara yang memiliki keanekaragaman sumber daya genetik ternak lokal, salah satunya yaitu ternak sapi. Populasi sapi potong di Indonesia yang secara kuantitatif mengalami peningkatan. Peningkatan populasi ini pada kenyataannya tidak diimbangi oleh peningkatan mutu genetik sapi lokal. Sapi Bali merupakan salah satu sapi potong lokal yang mengalami penurunan mutu genetik. Sehingga diperlukan upaya peningkatan mutu genetik sapi untuk meningkatkan produktivitas sapi lokal, salah satunya dapat dilakukan dengan perbaikan aspek genetik melalui persilangan dan seleksi. Seleksi pada ternak bisa dilakukan berdasarkan keragaman genotipe dan fenotipenya. Dugaan keragaman genetik sapi salah satunya dapat diteliti melalui pengamatan keragaman sifat kualitatif dan kuantitatif.

Salah satu sifat karakteristik genetik yang jarang diamati pada ternak adalah kergaman genetik sifat kualitatif. Keragaman kualitatif memberikan kontribusi yang besar pada program pemuliaan. Sifat kualitatif pada ternak bisa digunakan untuk membedakan ciri khas ternak individu yang satu dengan individu yang lainnya. Keragaman sifat kualitatif dapat menggambarkan ciri khas dari suatu bangsa. Keragaman sifat kualitatif dapat dilihat melalui warna kulit, warna rambut, bentuk tanduk, bentuk telinga, gelambir, bentuk tanduk, warna kaki dan bentuk tubuh fenotipe lainnya pada hewan. Sifat kualitatif adalah sifat penting dalam membentuk karakteristik rumpun sebagai alat untuk membentuk rumpun dan kegiatan seleksi.

Sapi Bali tersebar ke daerah - daerah disebabkan karena berbagai program pemerintah pusat dan daerah. Selain program penyediaan bibit sapi, penyebaran sapi bali juga disebabkan oleh program transmigrasi pemerintah (Indrijani, 2012). Salahsatu daerah transmigrasi yang dilakukan oleh pemerintah adalah Kolaka. Daerah transmigrasi yang tersebar diberbagai kecamatan yang ada di kolaka ternyata sebagian besar penduduknya beternak sapi Bali. Kecamatan Watubangga, Toari dan Tanggetada sebagai daerah sentra produksi ternak di kabupaten Kolaka memiliki potensi yang cukup besar sebagai lumbung ternak di Sulawesi Tenggara. Sapi lokal yang banyak dipelihara peternak di kabupaten Kolaka adalah sapi Bali. Sapi Bali betina banyak disilangkan dengan sapi Brahman jantan melalui inseminasi buatan (IB) untuk meningkatkan produksi daging sapi lokal (Susilawati, 2013).

Program Upsus Siwab (upaya khusus sapi indukan wajib bunting) adalah kegiatan yang terintegrasi untuk percepatan peningkatan populasi sapi secara berkelanjutan. Salah satu program utama dalam Upsus Siwab adalah peningkatan populasi melalui program IB. Program Upsus Siwab merupakan upaya untuk meingkatkan populasi sapi dalam rangka penyediaan ternak yang cukup dan ketersediaan daging dan telah dituangkan dalam Peraturan Menteri Pertanian Nomor 48/Permentan/PK.210/ 10/2016. Program Upsus Siwab diapresiasi oleh Pemda Kolaka, sehingga ditetapkan dua kecamatan sentra pelaksanaan program Upsus 
Siwab di kabupaten Kolaka. Semen sapi unggul Brahman telah di IB ke indukan sapi Bali yang tersebar dimasyarakat peternak. Karakteristik hasil IB dari pejantan Brahman dan indukan Bali belum diketahui performnsnya. Disisi lain, petani sangat antusius menjadikan hasil persilangan bangsa sapi tersebut sebagai bibit unggul. Tersebarnya sapi hasil persilangan Brahman dengan Bali menimbulkan ciri khas tersendiri yang menyimpan dari tetuanya. Perbedaan fenotipe antra indukan dan anak dari hasil persilangan menyebabkan peternak kesulitan mengidentifikasi ternak hasil persilangan. Sehubungan dengan hal diatas, penulis tertarik melakukan sebuah penelitian untuk mengidentifikasi karakteristik fenotip sapi hasil persilangan pejantan Brahman dengan indukan Bali pada program Upsus Siwab. Penelitian ini bertujuan untuk mengidentifikasi keragaman fenotipe bentukbentuk tubuh sapi hasil persilangan pejantan brahman dengan indukan sapi bali.

\section{METODE PENELITIAN}

\section{Waktu Penelitian}

Penelitian ini dilakukan di wilayah Kecamatan Watubangga, Toari dan Tanggetada, kabupaten Kolaka yang merupakan sentral pengembangan ternak sapi menggunakan inseminasi buatan pada program upsus Siwab. Penelitian ini dilakukan selama satu bulan. Mulai bulan Oktober - November 2021.

\section{Lingkup Penelitian}

Penelitian ini menggunakan sapi hasil persilangan pejantan Brahman dengan indukan Bali sebanyak 100 sampel.

Penelitian dilakukan dengan metode survey. Cara pengambilan sampel dengan purposive sampling. Data yang diambil adalah data primer dan sekunder. Data primer diambil dengan melakukan pengamatan secara langsung serta wawancara dengan peternak.

\section{Parameter Penelitian}

Parameter yang diamati pada penelitian ini berupa sifat kualitatif meliputi;

1. Garis punggung meliputi; tebal dan jelas, tebal dan tidak jelas, tipis dan jelas, tipis dan tidak jelas, tidak ada

2. Gelambir: bergelambir, tidak bergelambir, gelambir besar, gelabir kecil

3. Punuk: berpunuk, tidak berpunuk, punuk besar, punuk kecil

4. Bentuk Tanduk: ada, tidak ada, melengkung kedepan, melengkung kebelakang, melengkung keatas,

5. Bentuk telinga: tegak, tidak tegak, lebar, sempit.

\section{Analisis Data}

Data sifat kualitatif ditabulasi dan dihitung frekuensi fenotipnya. Frekuensi fenotip dihitung berdasarkan proporsi fenotip dengan rumus (Johari et al., 2009) sebagai berikut;

$$
\text { Frekuensi Sifat } \mathrm{A}=\frac{\sum \text { Sifat } A}{N}(100 \%)
$$

Keterangan:

$$
\begin{aligned}
& \mathrm{A}=\text { salah satu sifat kualitatif pada sapi yang } \\
& \text { diamati }
\end{aligned}
$$

\section{HASIL DAN PEMBAHASAN}

\section{Garis Punggung}

Hasil pengamatan terhadap 100 sampel sapi hasil persilangan pejantan Brahman dengan indukan Bali memiliki frekuensi fenotip garis punggung sebanyak $13 \%$ dan didominasi oleh sapi keturunan tidak memiliki garis punggung (87\%). Sifat tidak bergaris punggung pada sapi hasil persilangan diturunkan dari pejantan sapi Brahman sedangkan adanya garis punggung 
Tabel 1. Keragaman fenotipe bentuk-bentuk tubuh sapi hasil persilangan pejantan brahman dengan indukan bali

\begin{tabular}{lllcc}
\hline No & Fenotipe & Sifat Kualitatif & Jumlah & Persentase (\%) \\
\hline 1 & Garis Punggung & Tebal dan jelas & 2 & 2 \\
& & Tebal dan tidak jelas & 2 & 2 \\
& & Tipis dan jelas & 3 & 3 \\
& & Tipis dan tidak jelas & 6 & 6 \\
& & Tidak ada & 87 & 87 \\
\hline 2 & \multirow{2}{*}{ Gelambir } & Bergelambir & 67 & 67 \\
& & Tidak bergelambir & 33 & 33 \\
& & Gelambir besar & 3 & 3 \\
& & Gelambir kecil & 64 & 64 \\
\hline 3 & Punuk & Berpunuk & 22 & 22 \\
& & Tidak berpunuk & 78 & 78 \\
& & Punuk besar & 3 & 3 \\
& & Punuk kecil & 19 & 19 \\
\hline 4 & Bentuk tanduk & Ada & 91 & 91 \\
& & Tidak ada & 9 & 9 \\
& & Melengkung kedepan & 3 & 3 \\
& & Melengkung keatas & 77 & 77 \\
& & Melengkung kebelakang & 11 & 11 \\
\hline 5 & Bentuk telinga & Tegak & 32 & 32 \\
& & Tidak tegak & 68 & 68 \\
\hline
\end{tabular}

pada sapi hasil persilangan diturunkan dari indukan sapi bali. Menurut Agusriadi et al. (2019) pada punggung sapi Bali terdapat garis belut, yaitu bulu hitam yang membentuk garis memanjang dari gumba hingga pangkal ekor yang ditemukan pada sapi jantan maupun betina. Fenotipe garis punggung pada sapi hasil persilangan Brahman dengan Bali memiliki empat variasi sifat kualitatif yaitu garis punggung tebal dan jelas $2 \%$, tebal dan tidak jelas $2 \%$, tipis dan jelas $3 \%$, serta tipis dan tidak jelas 6\%. Hasil penelitian mengenai keragaman fenotipe bentuk-bentuk tubuh sapi hasil persilangan pejantan brahman dengan indukan bali disajikan pada tabel 1 .

\section{Gelambir}

Sapi hasil persilangan pejantan Brahman dengan indukan Bali memiliki gelambir dengan frekuensi fenotip sebanyak $67 \%$ dan tidak bergelambir sebanyak $33 \%$. Sifat bergelambir diturunkan dari pejantan yaitu sapi Brahman sedangkan sifat tidak bergelambir diturunkan dari indukan yaitu sapi Bali. Menurut Pane (1990), ciri khas sapi Brahman adalah berpunuk besar dan berkulit longgar, gelambir di bawah leher sampai perut lebar dengan banyak lipatan-lipatan. Sapi keturunan yang bergelambir terdiri dari dua variasi yaitu gelambir besar sebanyak 3\% dan gelambir kecil sebanyak $64 \%$ dari total sampel penelitian.

\section{Punuk}

Sapi hasil persilangan pejantan Brahman dengan indukan Bali didominasi oleh fenotipe yang tidak berpunuk (78\%) dibanding sapi hasil silangan berpunuk (22\%). Sifat berpunuk diturunkan dari pejantan sapi Brahman sedangkan tidak berpunuk diturunkan dari indukan sapi Bali. Sapi keturunan yang berpunuk terdiri dari dua variasi yaitu punuk besar 3\% dan punuk kecil sebanyak 19\%. Keragaman punuk hanya terletak pada ukurannya, yaitu punuk berukuran kecil dan besar dengan bentuk tegak ataupun sudah rubuh (Sudrajad et al., 
2013). Ditinjau dari segi produktivitas, besar kecilnya punuk mempengaruhi bobot badan sapi (Sudrajad et al., 2013; Dhita et al., 2017).

\section{Bentuk tanduk}

Bentuk tanduk sapi hasil pesilangan pejantan Brahman dengan indukan Bali terdapat lima variasi, yaitu sapi bertanduk sebanyak 91 ekor (91\%), tidak bertanduk 9 ekor (9\%), tanduk melengkung kedepan 3 ekor (3\%), melengkung ke atas 77 ekor (77\%), dan melengkung kebelakang 11 ekor (11\%). Sapi hasil persilangan Brahman dengan Bali dengan bentuk tanduk melengkung keatas lebih dominanan dari bentuk tanduk yang lainnya. Hasil penelitian ini sejalan dengan penelitian pada sapi Bali murni oleh Handiwirawan (2003) bahwa bentuk tanduk sapi Bali yang dominanan adalah melengkung keatas yang kemudian pada ujungnya melengkung keluar. Bradley dan Cunningham (1999) menyatakan bahwa terjadinya perbedaan bentuk tanduk pada sapi sekarang ini disebabkan karena hasil proses domistikasi yang terjadi. Menurut Ris (2012), keanekaragaman bentuk tanduk tidak hanya terjadi antar bangsa tetapi juga di dalam satu bangsa yang sama, keanekaragaman pada sapi bali membuat tanduk pada sapi bali pun ikut bervariasi. Faktor-faktor yang memengaruhi adanya perbedaan jenis tanduk yaitu jenis kelamin, umur, dan kekurangan kalsium.

\section{Bentuk Telinga}

Sapi hasil persilangan pejantan Brahman dengan indukan Bali memiliki bentuk telinga tegak sebanyak $32 \%$ dan telinga tidak tegak $68 \%$. Bentuk telinga tegak diturunkan dari indukan sapi Bali sedangkan telinga tidak tegak diturunkan dari indukan sapi Brahman.

\section{KESIMPULAN}

Sapi hasil persilangan pejantan Brahman dengan indukan Bali didominasi oleh sapi keturunan tidak memiliki garis punggung, memiliki gelambir, tidak berpunuk, bertanduk dan telinga tidak tegak.

\section{UCAPAN TERIMAKASIH}

Kami mengucapkan terima kasih kepada Direktorat Sumber Daya Kementerian Pendidikan, Kebudayaan, Riset dan Teknologi atas pendanaan Program Talenta Inovasi Indonesia tahun anggaran 2021.

\section{DAFTAR PUSTAKA}

Agusriadi, Kurnia, D., \& Anwar, P. (2019). Identifikasi fenotip pola warna dan pola bentuk tanduk sapi kuantan sebagai penciri plasma nutfah lokal Riau. Journal of Animal Center. 1(2), 46 -55.

Bradley, D.G., \& Cunningham, E.P. (1999). Genetics Aspects of Domestication. In: Fries, R. And Ruvinsky, A., editor.The genetics of Cattle. New York : CABI Publishing.

[Dirjend PKH] Direktorat Jenderal Peternakan dan Kesehatan Hewan, Kementerian Pertanian. (2016). Pedoman pelaksanaan Upaya Khusus Sapi Induk Wajib Bunting (Upsus SIWAB 2017). Jakarta: Kementerian Pertanian.

Dhita, N.T., Hamdani, M.D.I., \& Adhianto, K. (2017). Karakteristik kualitatif dan kuantitatif sapi peranakan ongol dan sapi simpo jantan pada gigi seri berganti 2 di Kecamatan Terbanggi besar Kabupaten Lampung Tengah. Jurnal Riset dan Inovasi Peternakan. $1(2), 28-32$.

Handiwirawan, E. (2003). Penggunaan Mikrosatelit HEL9 dan INRA035 sebagai Penciri Khas Sapi Bali. Tesis. Bogor: Institut Pertanian Bogor. 
Indrijani, A., Johar, Dudi, Wendry, S.P., Romi, Z., \& Hilmia. (2012). Kajian Identifikasi Sapi Lokal Jawa Barat dalam Mendukung Swasembada daging sapi. Laporan Penelitian. Bandung: Dinas Peternakan Provinsi Jawa Barat.

Johari, S., Sutopo, \& Santi, A. (2009). Frekuensi Fenotipik Sifat-Sifat Kualitatif Ayam Kedu Dewasa. Seminar Nasional Kebangkitan Peternakan. Hal. 606-616.

Pane, I. (1990). Pemuliabiakan Ternak Sapi. Jakarta: PT Gramedia Utama.

Ris, A., Suatha, I.K., \& Batan, I.W. (2012). Keragaman Silak Tanduk Sapi Bali
Jantan dan Betina. Buletin Veteriner Udayana. 4(2): 87-93.

Sudrajad, P., Subiharta, \& Adinata, Y. (2013). Karakter fenotipik sapi betina peranakan ongole Kebumen. Prosiding Seminar Nasional Teknologi Peternakan dan Veteriner: Inovasi Teknologi Peternakan dan Veteriner Berbasis Sumber Daya Lokal yang Adaptif dan Mitigatif terhadap Perubahan Iklim. Medan, 3-5 September 2013. Hal. 98-106.

Susilawati, T. (2011). Tingkat Keberhasilan Inseminasi Buatan dengan Kualitas dan Deposisi Semen yang Berbeda pada Sapi Peranakan Ongole. Jurnal Ternak Tropika. 12 (02), 15- 24. 